Prof. Dr. D. Miguel Rodríguez Pantoja

\title{
SOBRE LA TÉCNICA DESCRIPTIVA EN LA TRAGEDIA DE SÉNECA
}

UNIVERSIDAD DE CÓRDOBA 
Pretendo en esta modesta aportación al homenaje a Leocadio Martín Mingorance, excelente compañero y amigo y extraordinario filólogo, efectuar un repaso a la técnica descriptiva que despliega Séneca en algún pasaje de sus tragedias, como medio para conocer algunos de los recursos que pone a contribución el dramaturgo, nacido en Corduba hace dos mil años por estas fechas, en su controvertida forma de cultivar un género teóricamente al menos destinado a la escena.

Se ha repetido una y otra vez que las tragedias senecanas son obras cargadas de retórica, difícilmente representables (es frecuente objeto de discusión si alguna vez llegaron a ser vistas en un escenario'), con sus largas (e incluso larguísimas) tiradas de versos puestos en boca de alguno de los actores o del coro. Este hecho del abundante desarrollo vocal se ve además dificultado desde el punto de vista de la puesta en escena por el de que el actor no podía transmitir gestos faciales de ningún tipo.

Cierto que cabe toda una escenografía compleja y aparatosa, pero de poco sirve incluso esta escenografía y el movimiento (en todo caso limitado) de los actores si el autor no pone a contribución unas fuertes dosis de habilidad descriptiva, tanto de peripecias externas como internas al personaje (es decir, tanto de actuaciones individuales o colectivas, como de interiorización de pensamientos o pasiones) e incluso de diversos aspectos

1. Puede verse al respecto, por ejemplo, el apartado 4,1 de la Introducción a las traducciones realizadas por J. Luque Moreno: Séneca. Tragedias I, Madrid, 1987, pág. 44 y sigs., donde se plantean las diversas cuestiones en torno al asunto: «si Séneca las concibió o no para la escena»; «otra[...], muy próxima a la anterior, sería la de su representatividad, y otra más, la de si se representaron o no en Roma» 
de la naturaleza (paisajes, intervención de animales, fenómenos atmosféricos y otros), aún más difíciles de traer a cualquier escenario de forma convincente.

Es claro que Séneca domina esa técnica descriptiva, esa capacidad de evocar imágenes y sonidos con la palabra, que pone a contribución no sólo una y otra vez en las tragedias, sino también en el resto de sus obras.

Para demostrarlo propongo aquí el análisis de un par de textos; en ellos se podrá comprobar, espero, la validez y el alcance de estas afirmaciones. Es evidente que tal procedimiento habría de extenderse a otros muchos pasajes, pero por ahora nos conformaremos, en primer lugar, con una de las intervenciones del coro de troyanas en el Agamenón: concretamente los versos 710-719, para los cuales el poeta utiliza el metro habitual de las partes dialogadas, es decir, el senario yámbico.

Esta intervención va inmediatamente detrás de un parlamento de Casandra, la vidente condenada a profetizar siempre la verdad y no ser nunca creída, que le había tocado en suerte a Agamenón cuando los griegos se repartieron el botín una vez destruida Troya. Agamenón, que no quedó ajeno a su atractivo, la llevó consigo a Micenas, donde la cautiva se lamenta de sus numerosas desgracias familiares y personales.

Dice el texto latino:

$\begin{array}{ll}\text { Silet repente Phoebas et pallor genas } & 710 \\ \text { creberque totum possidet corpus tremor; } 711 & \\ \text { stetere uittae, mollis horrescit coma, } & 712 \\ \begin{array}{l}\text { anhela corda murmure incluso fremunt, } \\ \text { incerta nutant lumina et uersi retro }\end{array} & 714 \\ \text { torquentur oculi, rursus immoti rigent. } & 715 \\ \text { nunc leuat in auras altior solito caput } & 716 \\ \text { graditurque celsa, nunc reluctantis parat } & 717 \\ \text { reserare fauces, uerba nunc clauso male } 718 & \\ \text { custodit ore maenas impatiens dei. } & 719\end{array}$

Teniendo en cuenta lo que ya hemos dicho en reiteradas ocasiones respecto al hecho de que las versiones de los poetas han de hacerse en verso, y siguiendo pautas marcadas por investigadores como el Dr. Manuel Fernández Galiano $^{2}$, traduzco el pasaje utilizando versos con el mismo número de sílabas que tendría el esquema teórico del original (y que, como veremos en su lugar, Séneca no mantiene a lo largo de todo el texto, algo que, claro está, le

2. Por ejemplo,en «Un experimento de traducción rítmica horaciana», Bivium, Madrid, 1983, pp. 81-87. 
permiten las normas del género). Además, con el objetivo de subrayar el ritmo mediante un procedimiento tradicionalmente propio de nuestra lengua, procuro una rima asonante en los pares:
«Calla la febea: invade el livor su rostro $y$ un temblor insistente todo su cuerpo; sus cintas se atiesan, su pelo se eriza, ruge agitado en hondo rumor su pecho; su mirada incierta vacila y sus ojos, girados, se tuercen; después paran yertos. Ora alza al cielo más que nunca la frente y anda altiva, ora intenta forzar sus prietos labios, ora oprime la voz en la boca, ménade reacia a los divinos agüeros».

El total de palabras que ha utilizado Séneca en este coro es de cincuenta y seis; normalmente cada verso incluye cinco (con la excepción de 717, que lleva cuatro), sin contar las partículas no enclíticas, todas monosilábicas: un et en 710 y 714 delante de la cuarta (en este último además va precedido de final vocálico, por lo que no constituye sílaba métrica); un nunc correlativo en 716,717 y 718 , ocupando posición cada vez más avanzada dentro de su verso (primera, tercera y cuarta, respectivamente, con la última precedida por un sustantivo de su frase), y el in de 717, el único del fragmento que contiene dos partículas.

Precisamente la distribución de los vocablos y el esquema métrico presenta ya un aspecto curioso a destacar: los cinco primeros versos tienen todos doce sílabas, combinando dos trisílabos (o un monosílabo más un disílabo, en 710), nunca seguidos, con dos disílabos, aunque ninguno repite exactamente el esquema del anterior ${ }^{3}$; los otros cinco presentan trece (menos 716 , que tiene catorce) y las combinaciones son menos regulares. Para una mejor visualización de estos esquemas los escribo en columna:

\begin{tabular}{|c|c|c|c|}
\hline 710 & 2 & & 1 \\
\hline 711 & 3 & 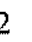 & \\
\hline 712 & 3 & 2 & \\
\hline 713 & 3 & 2 & $2^{4}$ \\
\hline 714 & 3 & 2 & $3^{5}$ \\
\hline
\end{tabular}

3. Los versos 713 y 714 se diferencian en que el segundo presenta elisión entre la tercera y la cuarta palabra, por lo que aquélla queda métricamente disilábica.

4. Como hemos dicho, aquí hay una elisión de un final de trisílabo vocálico.

5. No cuenta aquí métricamente el monosílabo et por ir precedido de final vocálico. 


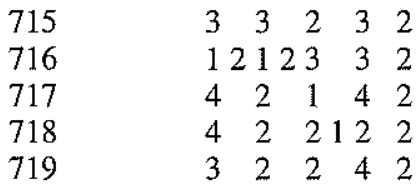

Es como si hubiera una especie de 'crescendo' en la descripción de los gestos, que en los cuatro últimos versos son realizados por la propia Casandra (leuat, parat, custodit), en tanto que al principio (excluido el silet del principio, que indica un aspecto auditivo y no visual) cuentan con otros protagonistas activos (pallor; tremor possidet; stetere uittae; horrescit coma; corda fremunt), quedando lumina y oculi como bisagra en el centro, con tres verbos (nutant para lumina; torquentur, rigent, ambos 'pasivos', para oculi, los únicos que, además de la protagonista, llevan más de un verbo). El verso más largo y de esquema más singular es aquél precisamente en el que se habla de algo insólito: nunc leuat in auras altior solito caput, con catorce sílabas por la inclusión de dos partículas de una, como hemos comentado.

Una vez señalada la distribución de los vocablos por su forma, pasemos ahora al estudio de la distribución por clases: predominan los verbos, con un total de veinte: doce en forma personal, siete participios (dos activos y cinco pasivos) más un infinitivo. A la vista de estas cifras, no es de extrañar que todos los versos tengan al menos uno en forma personal, excepto el penúltimo (donde hay un infinitivo destacado al principio tras su verbo regente que cierra el anterior, y un participio). Mientras los de la primera parte son preferentemente intransitivos, los de los cuatro versos finales, cuando Casandra toma el protagonismo directo, son transitivos.

La cantidad de sustantivos es algo menor: dieciocho. La mayoría designan, como era de esperar a la vista del contenido, partes del cuerpo. Están en todos los versos menos uno: genas cerrando 710; corpus en 711; uittae, tomadas como si fueran cosa propia de la cabellera de Casandra, en 712, verso que cierra coma; corda en 713; lumina en 714; oculi en 715; caput cerrando 716; fauces en 718; ore en 719. Dos se refieren a la protagonista, ambos relacionados de forma distinta con Febo, el dios que la castigó y la inspira: al abrir la intervención del coro, con ese adjetivo sustantivado que los asocia, Phoebas; al cerrarla, separándolos, con el matiz de locura y rebeldía que conlleva ese final maenas -impatiens- dei. De los cinco restantes, cuatro son abstractos: dos 'visuales', pallor, tremor (al principio: versos 710 y 711); dos 'auditivos', murmure, uerba (más espaciados: versos 713 y 718): queda auras (verso 716), que sólo hace dar plasticidad al significado de leuat. 
Mucho menor es el número de adjetivos: siete. Tras creber siguen cuatro referidos a partes del cuerpo, mientras los dos últimos, próximos entre sí por su significado, atañen a la protagonista; sólo uno, mollis, aplicado a coma en 713, es calificativo o epíteto 'ornamental'; el resto, espaciados a lo largo del texto, totum (con corpus, verso 711), anhela (con corda, verso 713), incerta (con lumina, verso 714), altior (verso 716) y celsa (verso 717) con el sujeto de la frase, que no es otro que la protagonista.

Todavía menor resulta el número de adverbios, que queda reducido a cuatro: repente (verso 710), retro (final del verso $714^{6}$ ), rursus (verso 715) y male (final del verso 718).

Este panorama nos permite hablar en principio de un pasaje lleno de movimiento, de meras acciones, donde se mezclan el elemento estático (semántica -stetere, silet, horrescit, rigent-, y morfológicamente, con formas pasivas, personales -torquentur-y, sobre todo, participiales -incluso, incerta, uersi, immoti, clauso ${ }^{7}$-) y el dinámico (siete verbos en forma personal, possidet, fremunt, nutant, leuat, graditur, parat, custodit; un infinitivo, reserare, más dos formas participiales activas, reluctantes, impatiens, situados los tres en la parte de mayor protagonismo directo de Casandra. En total, dos grupos de diez.

La descripción tiene como objetivo fundamental hacer «ver» (algo, como decíamos, físicamente imposible en el teatro romano) los movimientos físicos (sobre todo del rostro) y anímicos de una persona en circunstancias extremas, de ahí la aparición predominante de partes del cuerpo, que, para aumentar la sensación confusa y caótica, no aparecen descritas siguiendo su posición, antes bien, van alternando con otros elementos más generales: primero se mencionan las mejillas, luego el cuerpo en su totalidad, más tarde los cabellos y las cintas que llevan (empezando por éstas, lo cual acentúa la eficacia descriptiva de un hecho que se convierte por ello en insólito); a continuación una parte interna, que no se «ve», sino que se «oye» (murmure incluso), para detenerse más en los ojos (lumina, oculi, con un doble movimiento extremo: girar en las órbitas y quedar inmóviles).

Después de este panorama, se presenta la triple acción, también alternativa (nunc... nunc... nunc) de la protagonista, que afecta, de nuevo, a la cabeza, ahora tomada como un todo (caput), y a una parte de ella que hasta aquí no había aparecido y que constituye su principal tormento en cuanto que deja escapar palabras perjudiciales: la boca (fauces, ore).

6. Que en realidad forma un todo con la palabra que le precede, uersi.

7. Solito, en el verso 717 , tiene un valor adverbializado, por lo que puede ser incluído aquí. 
El motivo conductor es el silencio de Casandra, que empieza como una acción repentina, voluntaria y natural, abriendo la intervención del coro: calad nada más empezar, reforzado por el adverbio repente y sólo en tercer lugar la referencia a la causante del silencio que no es otra que la profetisa, es decir, la que, por serlo tiene el don de la palabra inspirada y, por culpa de sus desdenes a Febo, siempre acierta, pero nunca es escuchada (Phoebas).

El resto es la descripción física del rapto profético, que la propia Casandra intenta contener. Al final el silencio se convierte en algo violento, casi imposible ante la fuerza del dios que la inspira. Por eso el sonido juega escaso papel en este cuadro, y, como veremos, se resalta su presencia negativa.

Cabe dividir la descripción en una serie de cuadros o momentos:

I. Hecho repentinamente el silencio, el coro despliega

1) Un primer efecto visual que afecta, en un solo plano (un único verbo con dos sujetos), a la cara y al cuerpo; la secuencia es clara: el oyente percibe

a) primero la cara pálida (color: elemento 'estático'): pallor genas seguidos cerrando el verso.

b) después el cuerpo sacudido por un temblor (elemento 'dinámico'); el movimiento aparece distribuido a lo largo del verso, que tiene una perfecta estructura anular: creber -tremor (sendos disílabos) en los extremos (ocupando por tanto las posiciones privilegiadas del verso), totum - corpus (otra vez dos disílabos) en el interior y el verbo (possidet, trisílabo) en el centro.

2) Ahora la vista se dirige a la cabeza, donde nota

a) las cintas sorprendentemente tiesas (elemento 'estático'); el verbo está en 'pretérito perfecto' abriendo verso.

b) la cabellera, cuya suavidad, puesta en primer plano por el calificativo mollis (como decíamos el único del pasaje), adelantado a la forma verbal, hace más chocante el hecho de que se erice (ahora elemento 'dinámico', con el verbo en 'presente').

3) El coro hace percibir a continuación un anhelante movimiento del pecho (anhela corda abriendo verso), combinado con una elevación subrayada del sonido, que pasa a un primer plano doblemente señalado por la semántica (murmure... fremunt) y la repetición física del sonido $r$, las nasales e incluso la vocal $u$ : en las siete sílabas métricas finales, hay cuatro con nasal (la última por dos veces), cuatro con $r$, cuatro con $u$, combinadas de forma que, por ejemplo, $-m u$ - se da en tres, dos de ellas con una $r$ detrás, la tercera con $-n t$.

4) Ahora se vuelve la mirada al rostro, en esta ocasión a su parte más 
expresiva: los ojos (lumina -plano más alejado-, oculi -plano más próximo-), que primero se mueven frenéticos, llegando al máximo concebible (uersi retro, subrayado por la inversión del orden en la colocación de la parte adverbial, que además es destacada en la posición final de verso) y luego quedan inmovilizados y rígidos (nuevo juego semántico de refuerzo mutuo mediante la secuencia inmoti rigent con que termina este cuadro). De nuevo, pues, se combinan un elemento 'dinámico' y otro 'estático'.

II. Una vez el oyente ha «visto» el proceso de transformación de Casandra, se describen las acciones de ésta, a partir del verso 716, sin mencionarla expresamente, con tres frases introducidas por una misma partícula, nunc.

Son tres acciones, la primera doble, las otras dos paralelas, con el verbo cada vez más distanciado de la partícula introductoria ( $n u n c$ leuat; nunc reluctantes parat; uerba nunc clauso male custodit), que expresan:

1) Movimiento alternativo (aunque las acciones pueden interpretarse como sucesivas) de elevar la cabeza hacia el cielo (secuencia muy reforzada por el significado de los vocablos leuat in auras altior y por el hecho de que al final se anote lo insólito de tal acción en la protagonista: altior solito-) y caminar altanera (graditurque celsa). De nuevo elementos 'dinámicos', el primero de una acción momentánea («levanta la frente»), el segundo en cambio de una acción sostenida: «camina altiva».

2) Tal actitud es señal de una decisión que se antoja trascendente y que no es otra que «luchar con su garganta que se resiste a hablar» (reluctantis parat reserare fauces). Aquí se inicia el desenlace del pasaje con un 'movimiento contenido', no visible ni para el narrador.

3) Al final, esas palabras, tan importantes (uerba está destacado 'sacándolo' de su frase incluso delante del nunc), en una mal cerrada cárcel (nuevamente un reforzamiento mutuo del sentido de dos vocablos próximos en clauso /custodit), que sólo tras el verbo averiguamos que es la boca, las custodia una ménade (maenas) es decir, una mujer enajenada al ser poseída por el dios, al que no soporta.

Reaparece aquí la actitud del principio que, sin embargo, alcanza su culminación en ese 'dinamismo contenido': el verbo transitivo, parat, va detrás de un vocablo que lleva idea de «resistencia» y lo mismo sucede con la secuencia clauso male que cierra el verso siguiente y con la finăl, impatiens dei, donde el genitivo culmina el pasaje.

Los sucesivos cuadros, la tensión 'dinámico/ estático' que discurre a lo 
largo de toda la intervención del coro, transmite al oyente una imagen de la tensión que domina a Casandra en el momento en que, contra su voluntad, Febo intenta que la invada el delirio: si seguimos leyendo el texto del Agamenón, veremos que inmediatamente después de pasaje que hemos analizado toma de nuevo la palabra la troyana y, entre otras cosas, dice (720):

recede, Phoebe: iam non sum tua, «retírate, Febo, ya no soy tuya».

Como contraste con este pasaje de alta tensión, veremos ahora uno más lineal, lleno de movimiento 'dinámico'. Describe el acompañamiento de delfines a la flota doria cuando volvía de Troya después de la victoria. Discurre, formando parte de un parlamento mucho más largo (y singular bajo muchos aspectos ${ }^{8}$ ), puesto en boca del mensajero de Agamenón, Euribates, a lo largo de los versos 449-455 (igualmente senarios yámbicos) de la misma tragedia:

Tunc qui iacente reciprocus ludit salo tumidumque pando transilit dorso mare Tyrrhenus omni piscis exultat freto agitatque gyros et comes lateri adnatat, anteire naues laetus et rursus sequi; nunc prima tangens rostra lasciuit chorus, millesimam nunc ambit et lustrat ratem.
449

451

452

453

454

455

Como variante de la versión anterior, propongo aquí recurrir al simple romance castellano: téngase en cuenta, por una parte, el hecho formal de que el texto latino está en senarios yámbicos, versos cuyo esquema, como ya hemos señalado, suma al menos doce sílabas, aunque es fácil que tal cantidad sea superada en más de una ocasión; si utilizamos dieciséis para cada uno de ellos, podremos verter, apenas sin añadidos ni supresiones, todo el contenido del original. Además, con la rima asonante se evita un excesivo alambicamiento a la hora de seleccionar los vocablos y respetar las frases originales. Por otra parte, el fragmento está sacado de un largo texto cuyo tono épico queda patente en el contenido, íntimamente vincula-

8. Como señala J. Luque Moreno, op. cit, págs. 60-61, este parlamento «viene a ocupar casi por completo el acto tercero, acto que, como centro de las obras, suele estar dedicado a desplegar el climax emocional de los protagonistas». Lo cual, por cierto «es una señal más de la absoluta libertad con que se desenvuelve Séneca con respecto a la unidad estructural de la obra». 
do con los poemas homéricos. Como Séneca recurre aquí a un metro tenido por «popular» (aunque éste es un asunto a discutir, por supuesto en otras instancias), me parece por lo menos admisible esta opción:

\author{
«Entonces el pez que juega \\ estando la mar en calma \\ y con su curvado lomo \\ entre el ponto hinchado salta, \\ el delfín ${ }^{9}$, de hacer piruetas \\ no cesa sobre las aguas \\ y gira, $y$ con los costados \\ formando pareja nada, \\ feliz de ir ante las naves \\ y seguir luego su traza; \\ ora, retozando, el grupo \\ la proa primera alcanza, \\ ora ciñe e inspecciona \\ a la milésima ${ }^{10}$ barca».
}

El esquema de la distribución de palabras, bastante distinto del anterior en cuanto a las combinaciones, es el siguiente:

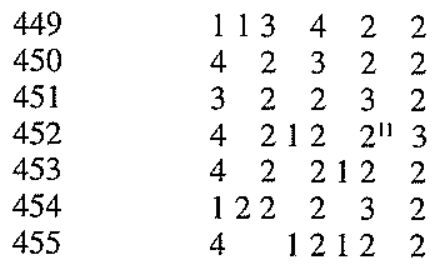

En cuanto al número de sílabas, hay tres versos con doce $(451,454$ y $455)$, tres con trece $(449,450,453)$ y uno con catorce $(452$, que por cierto termina en trisílabo); la distribución también es bastante distinta de unos versos a otros.

Por lo que respecta a las clases de palabras, el número de verbos y sustantivos está equilibrado: hay doce de cada uno (están presentes unos y

9. Nótese que el texto senecano dice «el pez tirreno».

10. Unos versos más arriba se ha hecho notar, en efecto, que las embarcaciones salidas de Troya alcanzan el millar.

11. La vocal final de lateri se elide, por lo que también aquí cabe hablar de vocablo disilábico a efectos métricos 
otros en todos los versos). Además, ocho adjetivos (sólo uno de ellos 'calificativo', pando), un adverbio (rursus) y siete monosílabos: un relativo, qui; tres $e t$; dos nunc y un tunc.

Con más brevedad que para el texto anterior, por no cansar con la minucia, repasemos los procedimientos narrativos a los que recurre Séneca en este pasaje:

Desde el punto de vista léxico el elemento marino inunda el texto, ocupando preferentemente las posiciones más destacadas de sus respectivos versos; así van al final, donde se percibe la caída rítmica, salo en 499 , mare en 450 , freto en 451 (obsérvese la cuasi sinonimia de estos tres vocablos, que cierran tres versos seguidos), adnatat (452) y ratem (455). Están además Thyrrhenus piscis, lateri ${ }^{12}$, naues, rostra.

Es de destacar también el carácter lúdico y ligero que dejan sentir no sólo ludit en el primero de los versos del pasaje, o laetus en 453 y lasciuit en 454 , sino también los diversos verbos que contienen la idea de «saltar», «dar vueltas», a los que ahora nos referiremos ${ }^{13}$.

Los tres primeros versos presentan varios elementos paralelos (que contrastan con la comentada desigualdad en la forma métrica): acabo de señalar la coincidencia en los vocablos finales: todos ellos llevan un adjetivo o participio 'adjetivado' en la primera parte del verso (iacente, pando, omni respectivamente) y en medio un verbo que evoca el jugueteo de los delfines (ludit, transilit, exultat). Sintácticamente los dos iniciales desarrollan una frase de relativo que describe al 'misterioso' pez capaz de jugar con el mar tranquilo y saltar a través (TRANsilit) del mar embravecido: el primer indicio visual que tenemos de él está en pando - dorso. Sólo después de percibir sus jugueteos y atisbar su lomo curvado se le identifica con el Thyrrenus... piscis, cuando salta por encima o fuera (EXsultat) del mar $^{14}$.

Los dos siguientes llevan, con sus respectivos sintagmas unidos por $e t$, una forma verbal al comienzo y al final: en 452 son dos terceras personas (agitat - adnatat), en 453 dos infinitivo (anteire - sequi). Este segundo pasaje sugiere la aproximación de los delfines singulares a las embarcaciones singulares, reproduciéndose el movimiento de nadar en paralelo (adnatat),

12. En la acepción de «costado de una embarcación».

13. Entre ellos exultare, que tienen también connotaciones lúdicas, como más atrde explicitará, entre otros, por ejemplo, Servio en su comentario aAen. 10,20 : exsultare uero [est] gloriari et laetum esse.

14. Sabido es que transilio y exsulto (simplificado gráficamente en exulto) remontan en último término al mismo verbo, salio, si bien el segundo lo hace a través del frecuentativo salto. 
adelantar a las naves (anteire) o seguir (sequi) en pos de su estela.

Finalmente, los dos últimos, donde la idea de pluralidad de los delfines se plasma en el chorus que cierra el verso 454, presentan un doble nunc con sendos verbos ante el vocablo final de cada uno de ellos (lasciuit, lustrat): ahora el jugueteo singular del pasaje anterior se convierte en el de dos grupos tomados como unidad: los delfines son una manada, las embarcaciones un todo con unos espolones delante y una barca cerrando el millar (millesimam al principio del verso, ratem, como ya hemos visto, al final).

Aquí no hay tensiones; sólo movimiento, en paralelo, con un sólo protagonista: el pez tirreno, el delfín, nunca solitario, que primero aparece a lo lejos y luego se aproxima a las embarcaciones jugando siempre, por unidades con cada una de ellas o en bandada con toda la flota.

Otros ejemplos aduciría si pensase que no basta con éstos. Al lector le toca decidir si la muestra resulta convincente. En caso contrario, quizá él pueda, aplicando este método, si no conoce otro mejor, encontrar argumentos que lo convenzan (y nos convenzan) de una cosa o de otra. 